\title{
POLIMINÓS NO ENSINO DE MATEMÁTICA DO SEXTO ANO: UMA EXPERIÊNCIA BASEADA NA INVESTIGAÇÃO ${ }^{1}$

\author{
TEACHING MATHEMATICS IN THE SIXTH YEAR THROUGH POLIMINÓS, \\ AN EXPERIENCE BASED ON INVESTIGATION
}

\section{Patrícia da Silva Lucas² e Leandra Anversa Fioreze ${ }^{3}$}

\section{RESUMO}

Este trabalho relata uma pesquisa baseada na utilização dos Poliminós, um quebra-cabeça geométrico constituído por figuras planas formadas pela justaposição de um número $\mathrm{n}$ de quadrados congruentes, de modo que pelo menos um quadrado permaneça conectado com todo o lado de outro quadrado. Por meio desta pesquisa, objetivamos responder de que maneira os Poliminós podem mobilizar alunos de sexto ano de Ensino Fundamental para a aprendizagem de áreas quadrangulares e identificação e reconhecimento de padrões. Foi elaborada e aplicada uma sequência de atividades de caráter exploratório-investigativa com alunos do sexto ano do Ensino Fundamental de uma escola pública da rede municipal de Porto Alegre, tendo como metodologia de ensino a Investigação Matemática.Os instrumentos de coleta de dados utilizados foram o caderno de registros contendo as observações realizadas ao final das aulas, as gravações dos encontros, bem como fotos das resoluções dos alunos com os Poliminós. A análise dos dados se baseou em buscar compreender o processo de resolução das atividades realizadas pelos alunos. Pode-se afirmar que o uso de Poliminós em sala de aula possibilitou a construção de um ambiente de interação entre docente/discente e discente/discente, reforçando, assim, o vínculo entre os estudantes e propiciando a aprendizagem de áreas quadrangulares e a identificação de padrões por meio do uso da tabela.

Palavras-chave: Investigação Matemática, Jogos, Poliminós.

\section{ABSTRACT}

This work presents a research based on the use of Poliminos, a geometric puzzle constituted by plane figures formed through the juxtaposition of a n number of congruent squares, organized in such way that at least one square remains connected to the whole side of another square. With this research, we aim at answering to what extent can Poliminós mobilize students from a sixth grade's elementary private school of Porto Alegre city's network, using as teaching methodology the Mathematics Investigation. The instruments of data collection used were the record book containing the observations made at the end of classes, the classes records, as well as the photos of the ending answers of the students challenges with Poliminós. It is possible to assure that the use of Poliminós in the classroom made possible for the construction of an environment of interaction between teacher/student and student/teacher, reinforcing the boundary between students and promoting the apprenticeship of mathematical squared areas and the identification of patterns using tables.

Keywords: Mathematical Research, Games, Poliminós.

\footnotetext{
${ }^{1}$ Artigo com bolsa BIC/UFRGS

${ }^{2}$ Licenciada em Matemática - UFRGS. E-mail: pathypsl@gmail.com

${ }^{3}$ Prof $^{a}$ Associada FACED - UFRGS. E-mail: leandra.fioreze@ufrgs.br
} 


\section{INTRODUÇÃO}

Esta pesquisa é baseada na utilização do material pedagógico Poliminós, um quebra-cabeças geométrico que possibilita trabalhar determinados conteúdos matemáticos, como perímetro, área, noções de álgebra e raciocínio combinatório. Ao conhecer melhor este material pedagógico e explorá-lo, puderam ser percebidas algumas de suas potencialidades a serem trabalhadas em diferentes níveis escolares.

Foi elaborada e desenvolvida uma sequência de atividades de caráter exploratório-investigativa com alunos do sexto ano do ensino fundamental de uma escola pública da rede municipal de Porto Alegre com o intuito de verificar de que maneira os Poliminós podem mobilizá-los para a aprendizagem da matemática, especificamente identificação de padrões e área de quadrados. A metodologia de ensino escolhida foi a Investigação Matemática, pois esta prima pelo caminho percorrido pelo aluno durante o processo de investigação, não priorizando o resultado final em que o mesmo é protagonista de sua própria aprendizagem (TRINDADE, 2017).

O estudo se justifica devido ao fato de que objetivamos que os alunos aprendam matemática através do envolvimento em sua aprendizagem, facultando-lhes um ambiente de aprendizagem que privilegie suas experiências. As atividades propostas com os Poliminós utilizando a metodologia de ensino proposta pela Investigação Matemática vai de encontro a estes aspectos. Além disso, de modo geral, os alunos apresentam dificuldades de aprendizagem e é nosso intuito proporcionar atividades que possibilitem uma participação mais ativa (ALVES, A. P. R. S., ALMEIDA, C. S., BRANDÃO, 2015).

A sequência é composta por seis atividades que abordam Geometria Plana (quadrados, retângulos, medidas de área e perímetro) e Álgebra, além do processo de construção dos Poliminós que envolve o raciocínio combinatório. Devido à sua forma geométrica, os Poliminós se caracterizam como um jogo de quebra-cabeças. Devido ao espaço destinado a este artigo nos deteremos a explicitar detalhadamente uma das atividades desenvolvidas, cujos conceitos mobilizados se relacionam com identificação de padrões e regularidades e áreas de quadrados.

\section{JOGOS E POLIMINÓS}

Estudiosos e pesquisadores ou professores da área da educação, ao longo da história da Educação, procuram criar situações que desafiem os alunos de modo a serem ativos no seu processo de construção de conhecimento; esses profissionais "concebem os jogos como estratégias pedagógicas favoráveis, inclusive para conceitos matemáticos" (MARQUES; PERIN; SANTOS, 2013, p. 2). Brandt (2014) em seu estudo sobre as concepções de lúdico, destaca alguns educadores matemáticos que trabalharam com jogos no ensino de matemática: Júlio César de Mello e Souza (Malba Tahan), Esther Pillar Grossi, Ana Cristina Rangel, Katia Stocco Smole e Regina Célia Grando. 
A importância do jogo no espaço escolar está fortemente alicerçada "na interação dos alunos e respeito entre o ganhador e perdedor, resultando numa prática educativa e recreativa como instrumento educacional, desenvolvendo assim o raciocínio lógico, físico e mental” (ROSADA, 2013, p. 11). Segundo Miranda (2000), o jogo é definido como atividade mental ou física, podendo utilizar material concreto ou não, tendo objetivos que são sustentados por regras, seja executado com brinquedos ou não. O autor ressalta a importância de manter-se o aspecto lúdico.

Grando (1995) classifica o jogo em seis tipos: jogos de azar, jogos de quebra-cabeças, jogos de estratégia, jogos de fixação de conceitos, jogos computacionais e jogos pedagógicos. Nos jogos de quebra-cabeças, na maioria das vezes, o participante joga sozinho e a sua solução é desconhecida para ele. Exemplos deste tipo de jogo são: charadas, enigmas, paradoxos, falácias, problemas simples e especificamente a Torre de Hanói e os Poliminós.

De acordo com Barbosa (2009) os Poliminós são geometricamente descritos como figuras planas formadas pela justaposição de um número $\mathrm{n}$ de quadrados congruentes, de modo que pelo menos um quadrado permaneça conectado com todo o lado de outro quadrado. Sua classificação é feita pela contagem de quadrados que compõem a peça, por exemplo: dois quadrados - Diminós, três quadrados - Triminós, quatro quadrados - Tetraminós, cinco quadrados- Pentaminós e assim sucessivamente (conforme figura 1).

Figura 1 - Poliminós do Monominó ao Pentaminó.

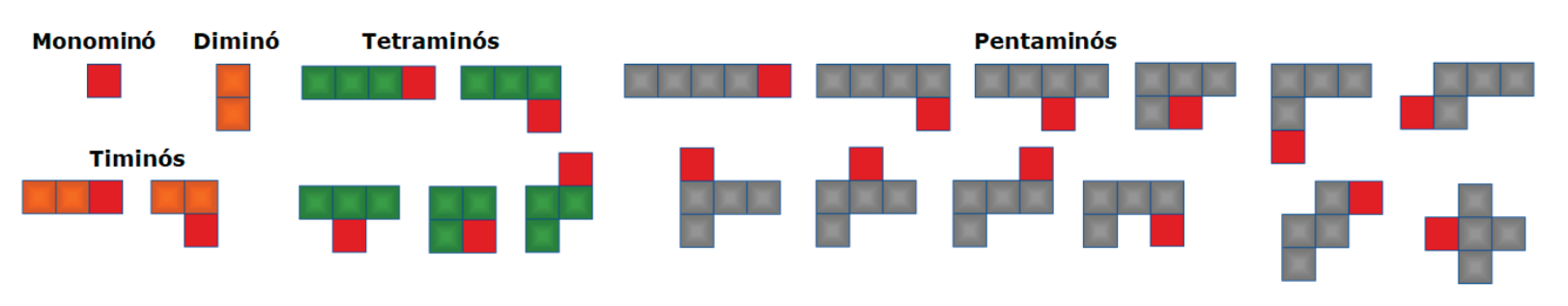

Fonte: Arquivo pessoal.

Segundo Barbosa (2009), o processo de construção dos Poliminós baseia-se nas possíveis combinações formadas por $n$ quadrados conectados por um lado pelo menos. Ou seja, a partir de um dos $n$ quadrados, através do deslocamento de um dos quadrados que compõem a peça, obtém-se o novo modelo, e assim sucessivamente até obter todas as prováveis combinações, adotando como regra não contabilizar como peças novas, peças obtidas por rotação e/ou simetria (L invertido e/ou virado).

Com essa proposta procura-se, além da atividade matemática, proporcionar desafios aos alunos através de quebra-cabeças que podem ser aplicados, com as devidas adaptações correspondentes, em diferentes níveis de escolaridade. O emprego com Poliminós oferece um ambiente social de cooperação, de investigação e serve de suporte para o processo de resolução de problemas. Devido os Poliminós serem dinâmicos, de fácil manipulação e lúdicos, acabam por se constituírem num material pedagógico interessante para serem utilizados em sala de aula. 


\section{INVESTIGAÇÃO MATEMÁTICA}

Para Ponte, Brocardo e Oliveira (2005, p. 13) investigar em Matemática é “[...] procurar o que não se sabe". Podemos afirmar que é ir de encontro ao desconhecido, de modo a dar oportunidade para o estudante fazer matemática como os matemáticos (cientistas). Por meio deste processo o discente pode escolher qual o caminho a seguir nas suas investigações; por vezes fazendo matemática de forma criativa, buscando a compreensão ao construir seu conhecimento matemático de maneira investigativa. Diferentes abordagens em atividades propostas podem contribuir para a resolução de problemas, e até mesmo para o enriquecimento da construção de conhecimentos matemáticos.

A investigação matemática é compreendida como um caminho "pelo qual pode ocorrer a aprendizagem matemática em um processo que busca um paralelo com a atividade dos matemáticos profissionais" (LAMONATO, 2007, p. 75). Nesse modelo o estudante ao se deparar com um problema, reitera os passos que um matemático (cientista) usa ao dedicar-se sobre seus ensaios (pesquisas): abordando os dados do problema proposto, testando inúmeras possibilidades que possam conduzir a resolução, analisando prováveis erros, procurando conhecimentos adquiridos anteriormente que possam auxiliar na solução, testando os resultados descobertos para compreender se errou e onde errou, corrigindo-se e por fim, produzindo um modelo. Para os cientistas matemáticos a investigação consiste em "descobrir relações entre objetos matemáticos conhecidos ou desconhecidos, procurando identificar as respectivas propriedades" (PONTE; BROCARDO; OLIVEIRA, 2005, p. 13).

As ideias abarcadas nesta aproximação do estudante com o cientista Matemático não estão focadas necessariamente no conhecimento produzido pelo aluno, e sim nas tentativas e condutas em elaborá-lo e na maneira de defrontar essa produção, na procura do conhecimento (SEGURADO; PONTE, 1998). Em outras palavras, a investigação não se foca em encontrar a "resposta certa" e sim, nos procedimentos adotados pelo indivíduo como por exemplo, na exploração de possibilidades, formulando conjecturas, aprendendo a argumentar (defender suas ideais) sobre seus resultados, se auto convencendo, bem como seus colegas.

Por outro lado, o ensino de matemática por vezes é marcado pela resolução repetitiva de exercícios pelos alunos e pela memorização, ignorando os inúmeros caminhos que um problema proposto possa ter em sua resolução, delimitando-se numa visão dualista da Matemática, “onde tudo está certo ou errado" (BORASI, 1990, apud SEGURADO; PONTE, 1998, p. 26). Em um estudo realizado por Frank (1998 apud SEGURADO; PONTE, 1998) são apontadas as cinco principais concepções dos alunos de $6^{\circ}$ a $8^{\circ}$ ano do ensino fundamental, sobre a Matemática e sua aprendizagem: (I) A matemática é cálculo; (II) Os problemas de Matemática são questões que se resolvem rapidamente e em poucos segundos; (III) Em Matemática, o objetivo é obter "respostas certas"; (IV) O papel do aluno é receber conhecimentos de Matemática e demonstrar que os adquiriu e (V) O papel do professor é transmitir conhecimentos de Matemática e verificar o que os alunos adquiriram. 
Indo na contramão destas concepções, a Investigação Matemática destaca a importância de o professor pesquisar/estudar/se envolver na construção ou na elaboração de propostas em que o aluno seja envolvido em seu processo de construção de conhecimento, não estando focado na memorização e/ou repetição de tarefas, bem como na resposta certa ou errada. Para Braumann (2002, p. 5):

\begin{abstract}
Aprender Matemática não é simplesmente compreender a Matemática já feita, mas ser capaz de fazer investigação de natureza matemática (ao nível adequado a cada grau de ensino). Só assim se pode verdadeiramente perceber o que é a Matemática e a sua utilidade na compreensão do mundo e na intervenção sobre o mundo. Só assim se pode realmente dominar os conhecimentos adquiridos. Só assim se pode ser inundado pela paixão "detectivesca" indispensável à verdadeira fruição da Matemática.
\end{abstract}

O autor sugere que aprender Matemática sem o uso da investigação é semelhante a andar de bicicleta sem praticar de fato, se atendo às observações e recebendo instruções sobre como conseguem; não sendo suficiente para aprender. É essencial que o sujeito tente, monte na bicicleta, cometa erros e aprenda com eles. De mesmo modo, para fazer Matemática não basta o aluno receber informações ou instruções sobre conceitos Matemáticos, sendo necessário trabalhá-los de forma investigativa, pois o fazer matemática está ligado intimamente com a sua investigação.

Outro ponto a se destacar na investigação seria o estudante poder igualmente seguir por caminhos nunca imagináveis e/ou cogitados pelo professor e que direcionam ao surgimento de resultados inesperados, devendo este estar atento a descobertas bem como dando continuidade (LAMONATO, 2007). Noutra situação, durante a investigação o discente poderá trilhar por caminhos que não lhe tragam sucesso; diante deste fato o professor não deve informar-lhe de que segue por um caminho infértil e sim dar-lhe um tempo, mas tomando o devido cuidado para que não que se prolongue por demais, a fim de que não venha a provocar no aluno o desânimo (desmotivação) pela tarefa. Desta forma, o professor pode fornecer dicas mais diretas e/ou relembrando problemas anteriormente realizados, cujas estratégias poderão ser utilizadas na resolução da presente tarefa proposta (FONSECA; BRUNHEIRA; PONTE, 1999).

De forma geral, existem três etapas de desenvolvimento para atividade investigativa: a introdução da tarefa, o desenvolvimento da investigação e a discussão/final dos resultados (PONTE; BROCARDO, OLIVEIRA, 2005). Serão descritas cada uma das três etapas conforme Fonseca, Brunheira e Ponte (1999, p. 2-6):

$1^{\underline{a}}$ etapa - Introdução da tarefa: nesta etapa o docente apresenta a tarefa à classe, podendo ser de maneira escrita, oral bem como auxiliada por algum recurso (software, material pedagógico, etc.).

2 a etapa - Desenvolvimento da investigação: esta etapa visa que o aluno desenvolva uma atitude investigativa (centrar a aula na atividade dos alunos, em sua exploração e ideia). Cabe ao docente adotar uma postura questionadora diante das solicitações de que é alvo.

$3^{\text {a }}$ etapa - Discussão dos resultados: momento em que os alunos apresentam suas descobertas e como as realizaram. Este é o momento oportuno para explanar ideias, estruturar alguns fechamentos e validar resultados. 
O registro desempenha um papel fundamental principalmente na etapa de discussão pois além do aluno apresentar seus resultados, o professor acompanha o que cada grupo realizou durante a investigação. Sob outra perspectiva, podemos apontar a importância dos estudantes em adquirirem a capacidade de comunicar-se matematicamente; devido a desenvolverem ideias próprias, permite que sejam trabalhados de maneira genuína e espontânea tais conhecimentos. Segundo Ponte, Brocardo e Oliveira (2005, p. 36):

Adicionar a esses motivos, haverá a acrescentar e recordar que a escrita dos resultados ajuda os alunos a clarificarem as suas ideias, nomeadamente a explicitar as suas conjecturas, e favorece o estabelecimento de consensos e de um entendimento comum quanto às suas realizações.

Para os autores, durante o processo de formulação e teste de conjecturas o docente precisa estar observando os alunos atentamente, para garantir que progridam no desenvolver das investigações.

\section{DESCRIÇÃo dA METOdOlOGIA, PRÁTiCA PEDAGógiCA E ANÁlise dOS RESULTADOS}

A pesquisa se enquadra como qualitativa, pois utiliza um método de investigação científica que enfoca os procedimentos e não o resultado final. Segundo Dalfovo, Lana e Silveira (2008, p. 9) a investigação qualitativa é: "[...] aquela que trabalha predominantemente com dados qualitativos, isto é, a informação coletada pelo pesquisador não é expressa em números, ou então os números e as conclusões neles baseadas representam um papel menor na análise". Devido ao caráter da pesquisa, compreende-se que os dados produzidos pelos estudantes não se quantificam em números, estando em conformidade com os objetivos da pesquisa que admite dados descritivos e interpretativos.

Durante o desenvolvimento das atividades propostas os alunos trabalharam em duplas ou com o grupo inteiro, possibilitando a ocorrência de momentos de discussão ou socialização de modo a propiciar a construção de um ambiente de interação entre aluno/aluno e professor/aluno, reforçando assim o vínculo entre os participantes. Para evitar a identificação dos participantes da pesquisa foram adotados nomes fictícios por exemplo, aluno(a) A, aluno(a) B, aluno(a) C, e assim sucessivamente, assim como as duplas receberam numerações (dupla 1, dupla 2, etc.). Foram vinte e sete o número de alunos participantes da pesquisa. Quanto a análise dos dados,de dez duplas, foram consideradas as sete que se mantiveram frequentes até o final da pesquisa. Para a prática pedagógica foram destinados dezoito períodos, sendo três períodos para a realização da atividade 4 .

A presente pesquisa utilizou como complemento e material de apoio para a análise de dados o caderno de registro (anotações feitas pela pesquisadora após as aulas), as gravações das aulas assim 
como fotos tiradas das resoluções realizadas pelos alunos com os Poliminós. Neste caderno de registros foram descritas algumas singularidades, tais como: questionamentos, indagações e interações entre aluno/aluno e professor/aluno ocorridas durante as práticas. A análise dos dados se baseou em buscar compreender o processo de resolução das atividades realizadas pelos alunos, a partir das estratégias explicitadas nos diálogos e nos registros escritos.

As atividades propostas foram produzidas em fichas sendo entregue aos estudantes no início de cada aula. Quanto às produções dos alunos, a turma desenvolveu apenas a primeira atividade em computadores e o restante nas fichas. Devido ao espaço destinado à produção deste texto, detalhamos somente uma das atividades propostas (atividade 4) sendo esta o foco de análise e discussão dos resultados.

Antes de iniciar a proposta a ser desenvolvida com os alunos foi exposto como seria desenvolvido o trabalho por meio da investigação e o que são atividades investigativas, sendo que a turma não tinha experiência com este tipo de abordagem, conforme informação da professora titular. Foram seguidas em cada atividade as etapas para o desenvolvimento da investigação.

- Atividade 1 - Exploração do material: Inicialmente, foi disponibilizado aos alunos quadrados coloridos em E.V.A. para que construíssem alguns "Poliminós", não sendo fornecidas quantas peças formariam cada um deles nem quais as condições necessárias para que seja caracterizado como "Poliminós". Nesta etapa inicial os alunos não sabiam o que eram Poliminós e construíram configurações com diferentes critérios. Aproveitando estas configurações foram caracterizados os Poliminós.

- Atividade 2 - Construção dos Poliminós no software PolyominoTiler: A atividade consistia em realizar a construção das peças desde o Monominó até os Pentaminós com a utilização do software (Disponível em: http://gfredericks.com/sandbox/polyominoes\#) e descobrir quais e quantas são as prováveis combinações distintas para cada um dos tipos de Poliminós.

- Atividade 3 - Construção de retângulos: A atividade consistia em construir retângulos a partir de Triminós em E.V.A. e verificar quantos Monominós compunha cada uma dessas respectivas construções por meio da contagem de quadradinhos (Monominós).

- Atividade 4 - Construção de quadrados: A atividade consistia em construir quadrados por meio de acréscimos de outros Monominós a partir de um Monominótendo como objetivo verificar se existe alguma relação entre a medida do lado e a medida da área do quadrado construído.

- Atividade 5 - Construção de quadrados ou retângulos: Nesta atividade, com base no Tetraminó (T) em E.V.A., foi solicitado que os alunos verificassem como construir quadrados ou retângulos e quais as medidas dos lados (conforme figura 2). 
Figura 2 - Atividade 5.

5- Utiliz ando apenas o Tetraminós (E.V.A.) do tipo:

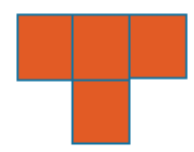

Seria possivel a criação de quadrados?

E a criação de retângulos?

\begin{tabular}{|l|l|}
\hline Dimensões & Desenho \\
\hline & \\
\hline & \\
\hline & \\
\hline
\end{tabular}

Fonte: Arquivo pessoal.

Atividade 6 - Construção de cercas: Esta atividade consistia em construir, a partir dos 12 Pentaminós, uma cerca em volta do maior campo retangular possível e calcular a área, bem como o perímetro externo e interno.

Nesta pesquisa será apresentada a análise da atividade 4, as demais atividades servirão como possíveis propostas a serem exploradas e ajustadas de acordo com nível escolar.

Para a realização da atividade 4, foi entregue uma ficha a cada dupla de alunos a ser preenchida, lápis de cor e papel milimetrado para a construção dos quadrados. Segue imagem da ficha contendo a atividade 4 (figura 3 ).

Figura 3 - Atividade 4.

1- No papel milimetrado e com hápis de cor, a partir do Monominó de hado 1 u.c. conforme ab aixo:

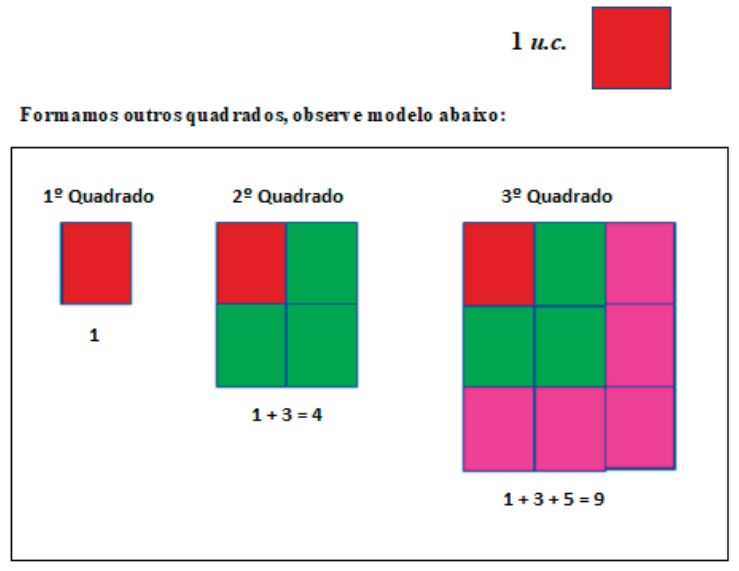

Conforme o padrão. Resok a:

a- Do $1^{0}$ quadrado para o $2^{0}$ quadrado, quantos Monominós foram acrescentad os?

b- Do $2^{0}$ quadrado para o $3^{0}$ quadrado quantos Monominós serão adicionados?

c- No $4^{0}$ quadrado será acrescentado quantos Monominós a mais em relação ao $3^{0}$ quad rad o? d- Observe que:

No 1ํquadrado temos 1 Monominó.

No $2^{-}$quadrado temos $?+?=$ ? Monominós.

No $3^{0}$ quadrado temos _

No $4^{9}$ quadrado temos __ Monominós.

E no $7^{0}$ quadrado temos__

0 que podemos a firmar em relação a soma dos Monominós?

e. $\mathrm{O} 3^{0}$ quad rad o é formad o por quantos Monominós? ___ E o lado desta peça é composto por quantos Monominós?

f- $04^{0}$ quadrado será form ad o por quantos Monominós?___ E o lad o desta peça será composto por quantos Monominós?

g- O 50 quadrado será formad o por quantos Monominós?___E o lad o desta peça será composto por quantos Monominós?

h- Qual a relação entre a medida do hado e a quantidade de Monominós que compõem o quad rad o?

Fonte: Arquivo pessoal. 
Primeiramente, foram construídas sequências de quadrados no quadro em uma determinada configuração espacial com participação da turma, até o terceiro quadrado de acordo com a construção apresentada na figura 4. Durante a exploração da construção dos quadrados os alunos não encontraram dificuldades para preencher a ficha contendo a atividade. No entanto, não conseguiam estabelecer a relação existente entre a medida do lado e a quantidade de Monominós que compõem cada um dos quadrados (item h da figura 3). Como era somente um período de aula e o próximo encontro seria no dia seguinte, a professora pesquisadora refletiu sobre a dificuldade encontrada pela turma neste último item e adotou uma tabela que foi agregada à proposta planejada.

Tabela 1 - Atividade proposta.

\begin{tabular}{|c|c|c|c|c|}
\hline $\begin{array}{c}\text { Número do } \\
\text { Quadrado }\end{array}$ & $\begin{array}{c}\text { Medidas dos } \\
\text { Lados (u.c.) }\end{array}$ & $\begin{array}{c}\text { Quantidade de } \\
\text { Monominós }\end{array}$ & Soma & $\begin{array}{c}\text { Quantidade de Monominós } \\
\text { Acrescentados }\end{array}$ \\
\hline & & & & \\
\hline & & & & \\
\hline & & & & \\
\hline & & & & \\
\hline & & & & \\
\hline
\end{tabular}

Fonte: Arquivo pessoal.

No encontro seguinte os alunos receberam a tabela a ser preenchida com o intuito de auxiliar os alunos a resolver o item h. A professora pesquisadora (P. P. ) questionou os resultados encontrados pelos alunos na tabela, com intuito de retomar a tarefa:

P. P. : Teríamos como descobrir as medidas do décimo quinto quadrado sem precisar construí-lo? E quantos Monominós teríamos no total?

Durante a resolução das atividades, havia quatro alunos que estavam debatendo a existência de alguma relação entre a medida do lado e a quantidade de Monominós, mas nada intuíram. A professora pesquisadora questiona os alunos acompanhando linha a linha (posição da linha) da tabela a partir do terceiro quadrado.

P. P. : Quais as medidas deste quadrado da linha 3?

Aluno G: Quadrado 3 por 3.

P. P. : E a quantidade de Monominós que o compõem?

Aluno G: 9 Monominós.

P. P. : Certo. E o quarto quadrado?

Aluno G: É 4 vezes que dá 16 Monominós. É só multiplicar os lados que dá o total de Monominós e a posição do quadrado me dá o tamanho dele.

P. P. : E o sétimo quadrado?

Aluno G: Seria da posição 7 que é o tamanho $7 \times 7$ que é igual a 49. 
P. P. : E se eu te perguntasse qual a medida do lado do décimo quadrado?

Aluno G: Seria 10.

P. P. : Teríamos como conferir este valor?

Aluno G: Pelo nosso desenho.

P. P. : Seguindo esta lógica quais seriam as dimensões do décimo quinto quadrado?

Aluno G: 15 por 15.

P. P. : E então existe alguma relação entre o lado e a quantidade de Monominós?

Aluno G: Sim é somente fazermos o lado vezes o outro.

P. P. : E o número de acréscimos de Monominós? Observem na tabela.

Aluno G: Tem 1, 3, 5, 7, 9, 11, 13, 15, ...

P. P. : Não te lembra nada?

Aluno G: É número... impar?

Aluno F: Sim. É sim, número ímpar.

Ao observar as tabelas preenchidas pelos alunos percebe-se que para descobrirem os valores referentes ao décimo quinto quadrado foram utilizadas as linhas da tabela como suporte (posição da linha).

Segue duas resoluções das duplas com a utilização de papel milimetrado (figura 4):

Figura 4 - Resoluções no papel milimetrado das duplas 7 e 4

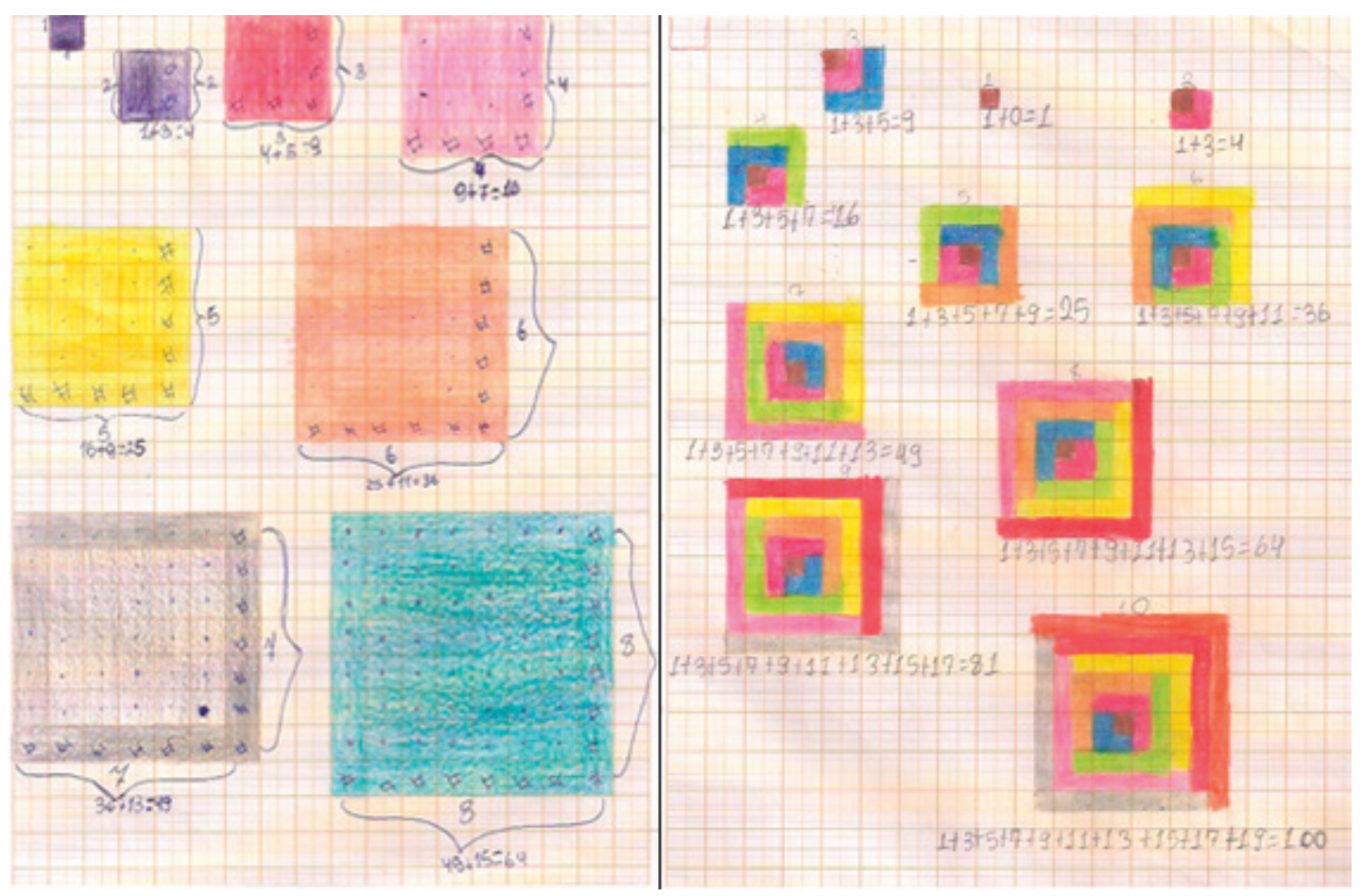

Fonte: Arquivo pessoal

Podemos notar na figura 4 que uma das estratégias adotadas para destacar os acréscimos de Monominós durante a construção dos quadrados, foi sinalizar com caneta em cima dos quadradinhos (à esquerda); outra estratégia foi colorir com cores distintas os acréscimos (à direita). 
Na sequência (figura 5), tem-se o registro na tabela da dupla 4:

Figura 5 - Tabela preenchida pela dupla 4

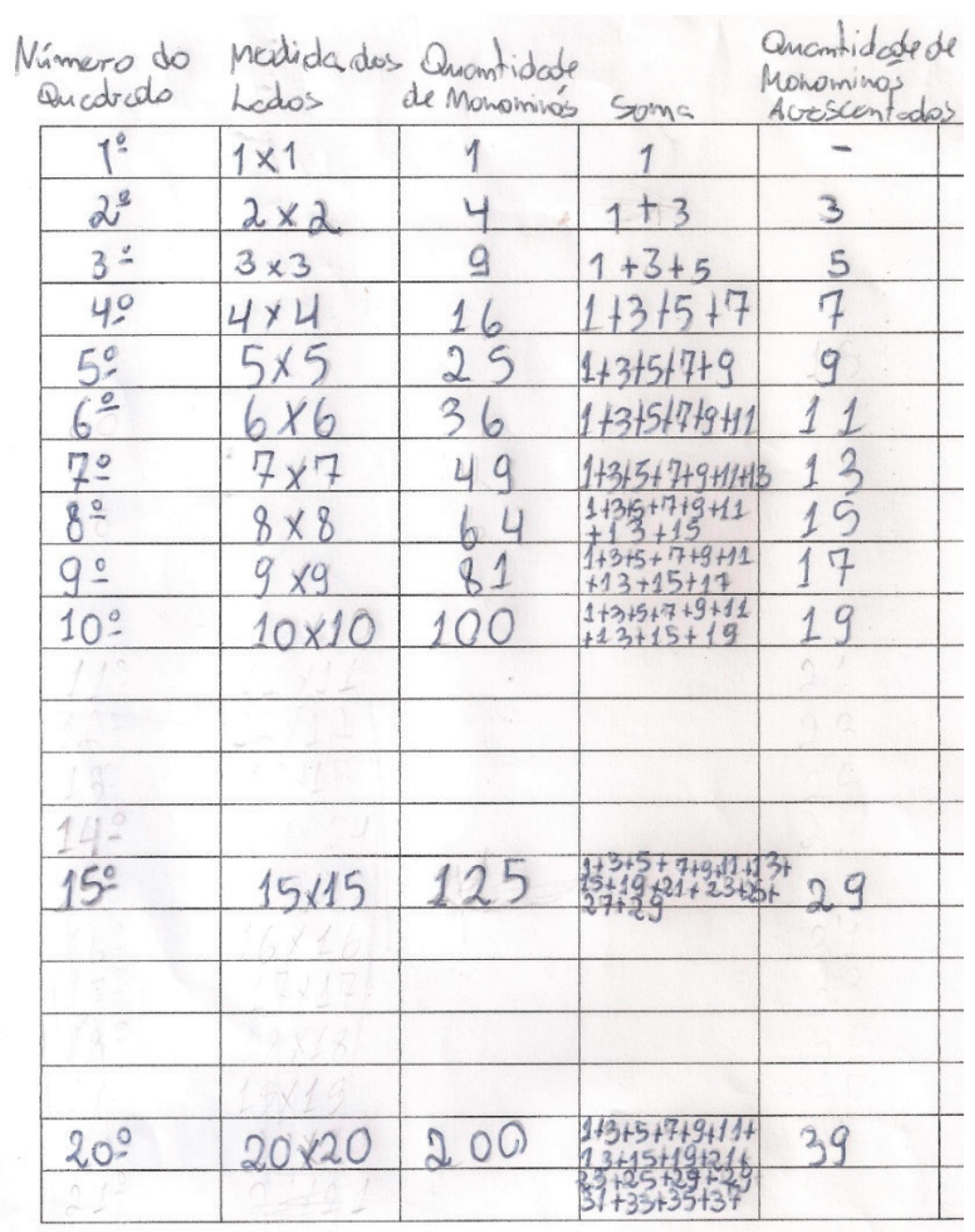

Fonte: Arquivo pessoal

Ao observar a figura 5, percebe-se que para descobrir os valores referentes ao décimo quinto e ao vigésimo quadrado foram utilizadas as linhas da tabela como suporte.

A partir das produções dos alunos, foi constado que:

- quatro duplas (duplas 3, 4, 5 e 6) conseguiram, com sucesso, realizar a atividade;

- uma dupla (dupla 7) não conseguiu intuir que a sequência de números ímpares corresponde ao número de Monominós acrescentados em cada novo quadrado construído, tendo realizado o restante da atividade com sucesso;

- duas duplas (duplas 1 e 2) conseguiram perceber que a posição na tabela é igual ao valor da medida do lado, tendo deixado as demais questões em branco.

Pode-se perceber por meio dos diálogos entre os alunos e com a professora pesquisadora que os alunos, em sua maioria, passaram a enxergar certos padrões indo além do que estava sendo solicitado na tarefa. Ponte, Brocardo e Oliveira (2005) desenvolvem a ideia de que no momento que estudamos 
determinado problema, “o nosso objetivo é, naturalmente, resolvê-lo. No entanto, para além de resolver o problema proposto, podemos fazer outras descobertas que, em alguns casos, se revelam tão ou mais importantes que a solução do problema original” (p. 1). Pode-se enumerar a identificação dos seguintes padrões: a posição na tabela é igual ao valor da medida do lado (exemplo: o quadrado da $5^{\circ}$ posição possui lado com medida 5 u. c.), a sequência de números ímpares corresponde ao número de Monominós acrescentados em cada novo quadrado construído; durante a discussão final foi descoberto em conjunto com a turma que o número de parcelas corresponde à ordem do quadrado.

\section{CONSIDERAÇÕES FINAIS}

Ao longo deste estudo buscou-se verificar de que maneira os Poliminós podem mobilizar alunos de um sexto ano do Ensino Fundamental para aprender matemática, e especificamente, na atividade 4, padrões e regularidades e áreas de quadrados.

Com base na análise do processo, pode-se verificar a apreciação dos Poliminós pelos alunos, havendo grande participação dos alunos frente a atividade proposta, assim como interação entre aluno/ aluno e professor/aluno. Possibilitando a construção de um ambiente de interação e aprendizado, reforçando o vínculo entre os alunos. Assim, observou-se que a sala de aula constituía um espaço agradável aos alunos; ou seja, por meio de um planejamento utilizando a metodologia da Investigação Matemática com os poliminós, constatou-se a participação e o envolvimento dos alunos em seu aprender.

Com relação à aprendizagem dos alunos, ao descobrir padrões e regularidades por meio do uso da tabela, percebeu-se que eles foram além do que foi solicitado inicialmente na atividade. Além disso, percebeu-se que os Poliminós favorecem a compreensão dos conceitos trabalhados como áreas quadrangulares, aliado ao desenvolvimento da percepção visual relacionadas com a identificação de padrões e regularidades e posterior generalização, além da visualização espacial. Além disso, constatou-se que o trabalho com Poliminós possibilitou interligar a geometria com outras áreas da matemática (atividade 4, Geometria com Álgebra), o raciocínio combinatório (na construção de peças) e a geometria das formas e medidas (medidas de comprimento e área). Abrantes (1999) afirma que ao utilizar-se da visualização e da manipulação de materiais, a geometria torna-se, porventura mais do que outro campo da Matemática, “especialmente propícia a um ensino fortemente baseado na realização de descobertas e na resolução de problemas, desde os níveis escolares mais elementares" (ABRANTES, 1999, p. 3).

Uma questão que apresentou ser um grande desafio para a autora foi quanto à condução durante as discussões em grupo ou em duplas, assim como nas intervenções durante o desenvolvimento das investigações. Este tipo de atividade, por ter um caráter aberto, acaba gerando certa insegurança, pois não há como prever todos os caminhos explorados pelos alunos, e tão pouca a resposta. Sua atividade docente até antes desta experiência, era de conduzir e direcionar o aluno frente aos conteúdos trabalhados. 
Com esse trabalho, pode-se compreender que o que importa na Investigação Matemática é o caminho percorrido pelo estudante durante o processo, independente do resultado final e que o aluno é protagonista de sua aprendizagem. Percebeu-se também que a metodologia de investigação requer organização e maleabilidade por parte do professor, de forma a compreender em que nível deverá ocorrer as intervenções, bem como a orientação das discussões.

Este estudo proporcionou verificar o potencial de atividades investigativas associadas ao uso de Poliminós, de modo a mobilizar o aluno na construção de seu próprio conhecimento. Além disso, promoveu o trabalho coletivo e colaborativo, visando tornar a matemática prazerosa, oportunizando descobertas e progressões dos alunos no desenvolvimento das investigações.

\section{REFERÊNCIAS}

ABRANTES, P. Investigações em geometria na sala de aula. Investigações matemáticas na aula e no currículo. Lisboa: APM, 1999.

ALVES, A. P. R. S., AlMEIDA, C. S., BRANDÃO, D. M. A Sequência Fedathi no ensino de geometria: o uso dos Pentaminós. Educación Matemática em las Américas Volumen 17: Talleres y minicursos. República Dominicana. p. 1-9, 2015. Disponível em: https://bit.ly/33socmZ. Acesso em: 07 de agosto de 2017.

BARBOSA, R. M. Bricadeiras, explorações e ações. Série: O professor em ação. Conexões e Educação Matemática. 2· ed. Belo Horizonte: Autêntica Editora, 2009.

BRANDT, N. Diferentes Modos de Compreender o Lúdico e suas Apropriações no Ensino de Matemática no Brasil. Porto Alegre: Universidade Federal do Rio Grande do Sul, 2014, 75 p. Trabalho de Conclusão (Licenciatura em Matemática) - Instituto de Matemática e Estatística, UFRGS, Porto Alegre, 2014.

BRAUMANN, C. Divagações sobre investigação matemática e o seu papel na aprendizagem da matemática. In: PONTE, J. P. ; COSTA, C.; ROSENDO, A. I.; MAIA, E.; FIEGUEIREDO, N.; DIONÍSIO, A. F. As atividades de investigação na aprendizagem da matemática e na formação de professores. Lisboa: SEM-SPCE, 2002.

DALFOVO, M. S.; LANA, R. A.; SILVEIRA, A. Métodos quantitativos e qualitativos: um resgate teórico. Revista Interdisciplinar Científica Aplicada. Blumenau, v. 2, n. 4, p. 01-13, Sem II. 2008. Disponível em: https://bit.ly/3khsPpQ. Acesso em: 10 de set. de 2017. 
FONSECA, H. BRUNHEIRA, L. PONTE. J. P. da. As actividades de investigação, o professor e a aula de matemática. In: Encontro Nacional de Professores de Matemática. Actas do Profmat(APM). Lisboa, 1999. Disponível em: https://bit.ly/39YFeur. Acesso em: 12 fev. 2018.

GRANDO, M. C. O jogo e suas possibilidades metodológicas no processo ensino/ aprendizagem da matemática. Campinas: Universidade Estadual de Campinas, 1995, 175p. Dissertação (Mestrado em Educação), Universidade Estadual de Campinas, Campinas, 1995.

LAMONATO, M. Investigando Geometria: Aprendizagens de Professoras da Educação Infantil. São Carlos: Universidade Federal de São Carlos, 2007. 245p. . Dissertação (Mestrado em Ciências Humanas), Universidade Federal de São Carlos, São Carlos, 2007. Disponível em: https://bit.ly/ 2DDcHhA. Acesso em: 10 fev. 2018.

MARQUES, M. de C. P. ; PERIN, C. L.; SANTOS, E. dos. Contribuição dos jogos matemáticos na aprendizagem dos alunos da $2^{\circ}$ fase do $1^{\circ}$ ciclo da Escola Estadual 19 de Maio de Alta Floresta-MT. Refat - Revista Eletrônica da Faculdade de Alta Floresta, Alta Floresta,v. 2, n. 1. 2013. Disponível em: https://bit.ly/39ZxCI8. Acesso em: 16 fev. 2018.

MIRANDA, S. Prática pedagógica das séries iniciais: Do fascínio do jogo à alegria de aprender. Brasília: Universidade de Brasília, 2000, 187 p. Dissertação (Mestrado em Educação), Universidade de Brasília, Brasília, 2000.

PONTE, J. P. da; BROCARDO, J. OLIVEIRA, H. Investigações matemáticas na sala de aula. Belo Horizonte: Editora Autêntica, 2005.

ROSADA, A. M. C. A importância dos jogos na educação matemática no ensino fundamental. Medianeira: Universidade Tecnológica Federal do Paraná, 2013. 45p. . Monografia de Especialização (Pós Graduação em Educação: Métodos e Técnicas de Ensino), Universidade Tecnológica Federal do Paraná, Medianeira, 2013. Disponível em: https://bit.ly/2DmaV4P. Acesso em: 19 fev. 2018.

SEGURADO, I.; PONTE, J. P. da. Concepções sobre a Matemática e trabalho investigativo. Quadrante, Lisboa, v.7, n.2, 1998. Disponível em: https://bit.ly/30rraX4. Acesso em 13 out. 2017.

TRINDADE, A. Pense Matemática | Investigação Matemática por Ângela Trindade. 2017. (3m 56s). Disponível em: https://youtu.be/lYeQ_8Fl-MI. Acesso em: 19 de fev. de 2018. 